\title{
Overview: Microbial amendment of remediated soils for effective recycling
}

\author{
Soo-Bin $\mathrm{Kim}^{1}$ and Jun-Boum Park ${ }^{1}$ \\ ${ }^{1}$ Department of Civil and Environmental Engineering, Seoul National University, Seoul, Republic of \\ Korea
}

\begin{abstract}
In recent years, various methods are being considered with appropriate amendments, not with conventional reclamation to recycle deteriorated soils after remediation as agricultural addition, backfilling and construction materials etc. Among these amendments, microbial amendments with effective microorganism(EMs) are known to improve soil qualities such as fertility, strength and toxicity to be recycled into possible utilizations. This study indicates the possibility of recycling the remediated soils by using these EMs most efficiently. Soil samples will be collected from contaminated sites with either heavy metals or petroleum and will be remediated by bench-scale soil washing and thermal desorption. And then the remediated soils will be treated with easily obtainable inocula, substrates (culture media) near our life and they are compared with commercial EM products in terms of the cost and efficiency. Also, after treating with a number of mixing ratios, soil properties of (1) fresh, (2) contaminated, (3) remediated (4) amended soils will be evaluated based on soil quality indicators depending on demands and the optimal mixing ratios which are effective than commercial EM products will be determined. The ratio derived from pre-tests could be applied on the remediated soils with pilot-scale in order to assess suitability for recycling and characterize correlation between soil properties and microbial amendments regarding contaminants and remediation, and furthermore for modelling. In conclusion, application of the established models on recycling remediated soils may help to dispose the remediated soils in future, including environmental and ecological values as well as economical values.
\end{abstract}




\section{Introduction}

These days, soils have been significantly contaminated with contaminants such as heavy metals or petroleum any times from everywhere since urbanization and industrialization. Various methods like soil washing and thermal desorption etc. are used to remediate the contaminated soils and also aggressive and subsequent remediation methods are being used to increase remediation efficiency. They remove contaminants from the soils by utilizing physiochemical, biological, and thermal processes and can satisfy soil remediation standards within a limited time. However, such process could affect soil properties and degrade the quality of the soils. Effects of soil washing and thermal desorption, which are the most frequently used remediation methods, on the physiochemical and biological properties of remediated soil were being investigated by many previous studies. After soil washing, particle size, water holding capacity, electrical conductivity (EC), exchangeable cations (potassium, calcium, magnesium), organic matter, cation exchange capacity (CEC), total nitrogen, total microbial number and nutrients (manganese, zinc) bioavailability were decreased. And after thermal desorption, acidity, EC, exchangeable cations, organic matter, $\mathrm{CEC}$, total nitrogen, available phosphate, total microbial number were decreased (Yi et al. 2012, 2013). With the increase of EDTA concentration, the maximum void ratio, soil cohesion, arrangement directionality and the content of illite, albite and montmorillonite decreased while the consolidation coefficient, compression modulus, internal friction angle, plastic limit, elastic limit and content of quartz increased (Wang et al. 2013). Aggressive remediation with high temperature affect the particle size distribution, mass loss, mineralogy and permeability of the soil and it is very likely to affect the dynamic behavior such as infiltration, permeability and shear behavior depending on the sample composition, sand only or sand-clay mixture (Zihms et al. 2013). The range of maximum dry densities under compaction remained reasonably consistent; however, a clear reduction in the optimum moisture content was observed in the thermally treated soils (Khan et al. 2014). Micro CT images have shown that high temperature smouldering remediation makes the grain surfaces significantly smoother and this change may explain changes that have been observed in dynamic soil grain-grain and grain-water interactions such as permeability, cohesiveness, and shear strength of soils (Switzer et al. 2013, 2015). These results show that the remediation processes used to clean contaminated soils affect the soil qualities.

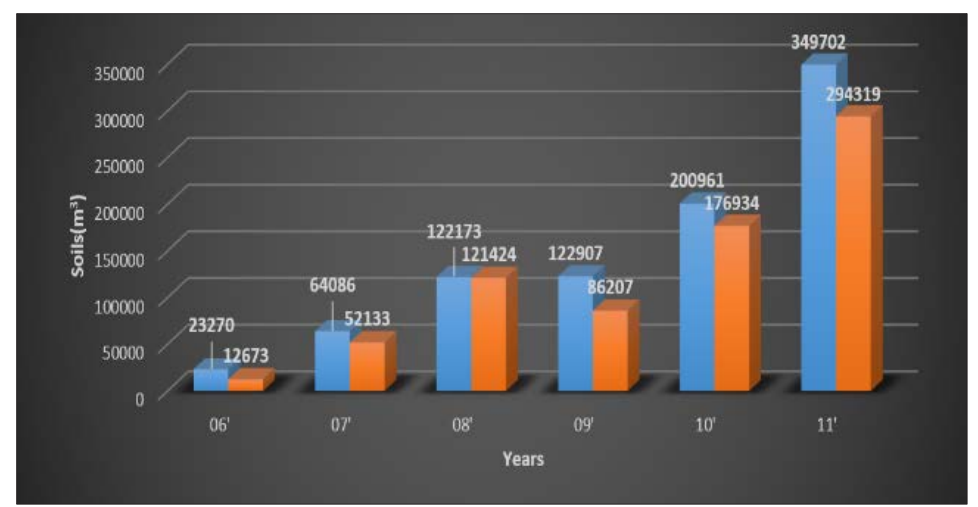

Figure 1 Amounts of excavated soils and remediated soils in Korea ('06-'11) 


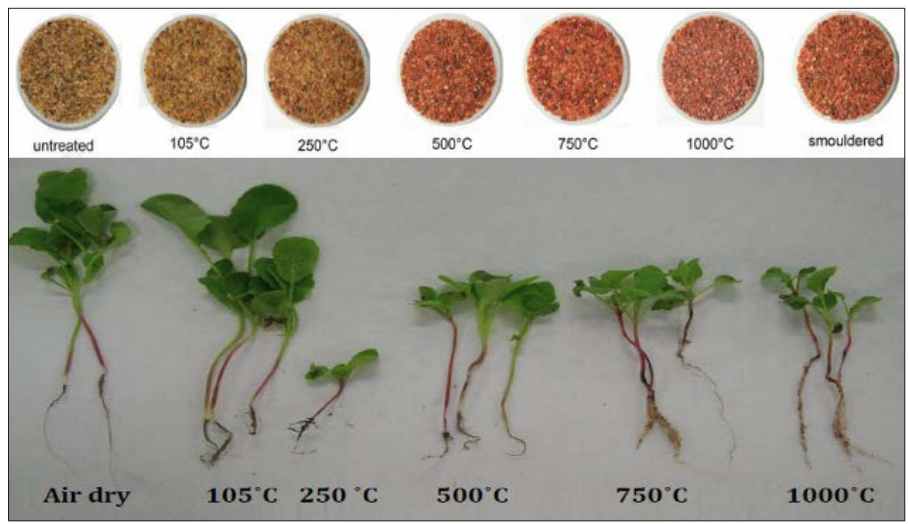

Figure 2 Comparison of the soil color and aboveground length of plants between thermally treated soils with different temperatures and natural soils (Switzer et al. 2015)

Commonly, the most of remediated soils have been used for backfilling and landfilled. Due to high amount of the remediated soils and treatment costs, the possibility to utilize the remediated soils in for example agricultural soil addition, backfilling and construction materials etc. would be desirable. However, there are some functional problems to recycle the remediated soils as diverse usages. The remediated soil could not satisfy the soil criteria for sources of demands and be managed in insufficient regulation. The remediated soils have several problems which are infertility, low strength and residual toxicity depending on demands. For agricultural addition and landscape, it may be inadequate in terms of fertility and toxicity. For construction materials, strength and toxicity. For replantation in roadside cutting-slope, strength and fertility.

In response to the change in soil properties by remediation, the soil material has been amended technologically and ecologically. To utilize the cleaned soil for healthy and more value-added purposes, soil improvement and amendment are needed. Among the amendments, microbiological techniques have potential capacities not to amend the remediated soils, but also to exert multiple functions. The uniqueness of microorganisms and their often unpredictable nature and biosynthetic capabilities, given a specific set of environmental and cultural conditions, have made them solve particularly difficult problems in ecosystem.

For many years, soil microbiologists and microbial ecologists have tended to separate soil microorganism into beneficial and harmful depending on their functions and how they affect soil quality. The microorganisms which are beneficial to soils were suggested by Teruo Higa, University of the Ryukyus, Japan and they were referred to as 'Effective Microorganism (EM)'. The concept of EM means mixed cultures of beneficial and naturally-occurring microorganisms that can be applied as inoculants to increase the microbial diversity of soils. A series of inoculations are made to ensure that the introduced microorganisms continue their dominance over the indigenous populations. Originally, EMs was used for agricultural compost and soil conditioning and these include the suppression of plant pathogens and diseases, conservation of energy in plants, solubilization of soil minerals, soil microbialecological balance, and biological nitrogen fixation (Higa et al. 1991). Furthermore, it has been developed as alternative uses for a more sustainable soil management.

And also EMs could be used for bioremediation to remove residual trace contaminants in the remediated soils. TPH concentration before EM treatment was $323.8 \mathrm{mg} / \mathrm{kg}$, whereas TPH concentrations on 2 days after EM treatment was $102.1 \mathrm{mg} / \mathrm{kg}$ and on six days after EM treatment TPH was $91.3 \mathrm{mg} / \mathrm{kg}$ (Lee et al., 2008). But for inorganic toxic compounds such ad heavy metals, microbes are unable to simplify them into harmless compounds, and they should be used according to their specialization for the type of contaminants. Some specific 
microorganisms are known to reduce the toxicity by different mechanisms such as biosorption, metal-microbe interactions, bioaccumulation, biomineralisation, biotransformation and bioleaching (Dixit et al. 2015).

According to recent geo-biological researches about Microbially Induced Calcium Carbonated Precipitation (MICCP), an alkalophilic soil bacterium with a highly active urea enzyme consumes urea within the microbe, decomposing it into ammonia $\left(\mathrm{NH}_{3}\right)$ and carbon dioxide $\left(\mathrm{CO}_{2}\right)$. These chemicals diffuse through the cell wall of the gram positive microbe and into the surrounding solution. The reactions spontaneously occur in the presence of water; ammonia is converted to ammonium $\left(\mathrm{NH}_{4}^{+}\right)$and carbon dioxide equilibrates in a $\mathrm{pH}$ dependent manner with carbonic acid, carbonate and bicarbonate ions. The net increase in $\mathrm{pH}$ is due to hydroxyl ions $\left(\mathrm{OH}^{-}\right)$generated from the production of $\mathrm{NH}_{4}^{+}$which exceeds the available $\mathrm{Ca}^{2+}$ for calcite precipitation. This provides the alkaline environment and carbonate required for the precipitation of calcite $\left(\mathrm{CaCO}_{3}\right)$. The negatively charged bacterial cell is attracted to the soil particle surface due to a higher concentration of nutrients adjacent to surfaces in addition to the physicochemical properties of both the bacterial cell and soil particle (Dejong et al. 2010). When diluted commercial EM and EM ceramics are mixed with cement, the compressive strength at 3 days and 7 days was found to be larger by 30 to $50 \%$ than that of control (Sato et al. 2000).

Culture-dependent microbes already contribute much to human life, yet the latent potential of vast numbers of uncultured and thus untouched microbes, is enormous (Patil et al. 2014). Indigenous microorganisms are a group of innate microbial consortium that inhabits the soil and the surfaces of all living things. Indigenous microorganisms inhabit the soil with the abilities of biodegradation, bioleaching, biocomposting, nitrogen fixation, and improving soil fertility and they are being used effectively as microbial inoculants that could exist naturally in soil or added as microbial inoculants to soil where they can improve soil quality (Kumar et al. 2015). The use of indigenous inoculum isolated from local soils resulted in a higher arbuscular mycorrhizal fungal diversity in the root of plants growing in the remediated soil with EDTA chelating agent extraction compared to the ones amended with the commercial inoculum (Maček et al. 2016).

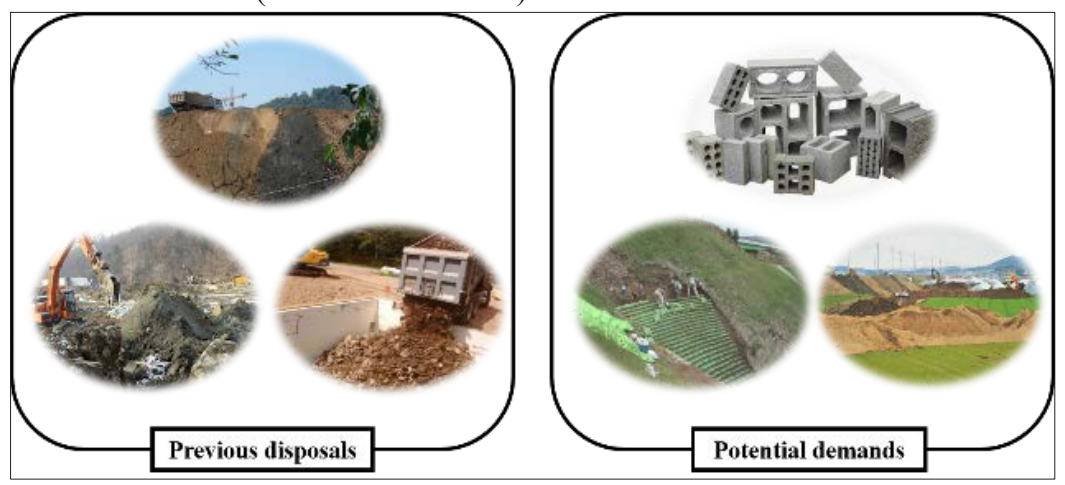

Figure 3 Expected demands of the microbially amended soils

\section{Materials and Methods}

\subsection{Materials}

\subsubsection{Soil}


Soil samples will be collected from three different points of soil surface $(0-20 \mathrm{~cm})$. The soil samples will be collected from contaminated sites with heavy metals and petroleum respectively. Non-contaminated soil will also be collected from the arable land. The sampling site is located close to an industrial area in Korea and was used for cultivating before.

\subsubsection{Microorganism}

The commercial EM and EM ceramic will be obtained from the Korean EM Research Organization (Busan, Republic of Korea).

Other beneficial microorganism will be isolated from indigenous solids like cultivated soils, contaminated soils and concrete structure.

\subsubsection{Culture media}

The commercial molasses will be also obtained from the Korean EM Research Organization.

Chemical agar medium containing nutrient broth and inorganic compounds will be produced by using other researches recipe depending on microorganisms.

Microorganisms are effective only when they are presented with suitable and optimum culture. But, chemical agar medium is expensive to be feasible in real situation. Some organic wastes like food wastes, agricultural by-products and rice water processed with grinding or autoclaving could be used as economical substrates to cultivate microorganism. Addition of an organic compost and liquid swine manure for the removal of soil TPH showed higher efficiency as $84.4 \%$ and $92.2 \%$ respectively than inorganic nutrients of $80.2 \%$ (Kim et al. 2008).

Also, soil solution extracted from indigenous soil by mixing and centrifuging may be effective media to adapt microorganisms to the remediated soil.

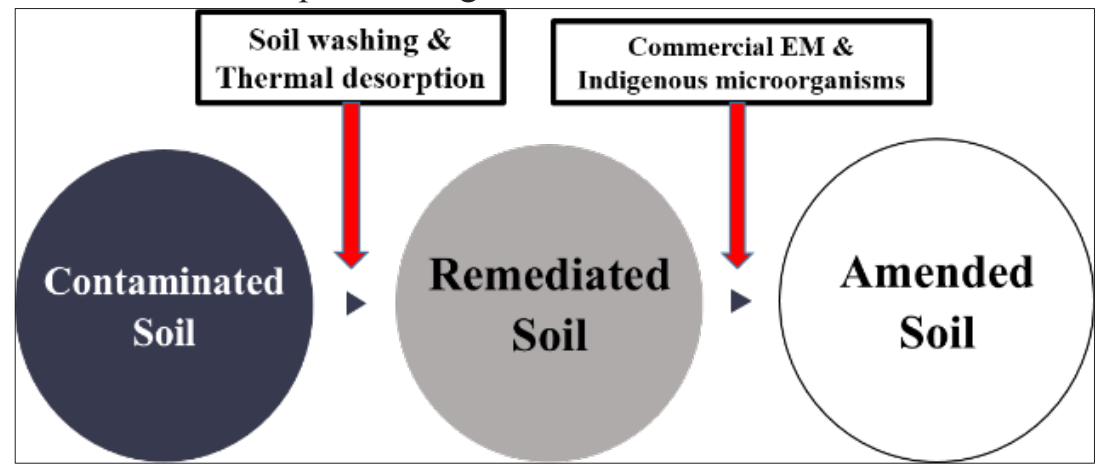

Figure 4 Schematic process of remediation and amendment

\subsection{Methods}

\subsubsection{Soil remediation}




\subsubsection{Soil washing}

The soil sample contaminated with heavy metals will be remediated by batch test with EDTA solution as reported by Lei et al. The air-died soil samples will be sieved using a sieve $(2 \mathrm{~mm})$ to remove large particles, then thoroughly mixed to ensure uniformity. The tubes containing $2 \mathrm{~g}$ soil samples and $20 \mathrm{ml}$ EDTA $(0.075 \mathrm{mM})$ will be shaken at a speed of $280 \mathrm{rpm}$ at room temperature for $3 \mathrm{~h}$ and 3 cycle. The suspension will be centrifuged at $5000 \mathrm{rpm}$ for $15 \mathrm{~min}$ and the supernatants will be filtered through a $0.45 \mu \mathrm{m}$ membrane for heavy metal analysis. Chen et al. compared the extraction efficiency of several chelating agents for heavy metal contaminated soil, results showed that extraction efficiency of $\mathrm{Cd}$ increased with the increasing eluent concentration, extraction efficiency of the same eluent concentration followed the order EDTA $>$ DTPA $>$ NTA $>$ PA $>$ CA $>\mathrm{CD}>\mathrm{HCl}$, but only EDTA can achieve the desired leaching effect on $\mathrm{Pb}$ and $\mathrm{Cd}$.

\subsubsection{Thermal desorption}

The soil sample contaminated with petroleum will be also remediated by remedy screening test as reported by US. EPA. Among these tests, static tray test full-scale thermal treatment systems. Briefly, An aliquot of 100-500g of fine earth fraction $(<2 \mathrm{~mm})$ of contaminate soil is heated at $760^{\circ} \mathrm{C}$ in a muffle furnace equipped with an electronic temperature controller. The depth of the soil should be kept at a minimum to eliminate temperature and concentration gradients within the soil bed. The time to reach the target temperature should be minimized to a practical laboratory timeframe such as 5 to 10 minutes. Longer time may be required depending on the specific contaminants present in the soil.

\subsubsection{Microorganism Isolation and Cultivation}

Base on the collection sites, the process of collection and isolation methods are different as they vary from place to place.

For isolation of bacterial strains, $1 \mathrm{~g}$ of indigenous soils will be homogenized with $9 \mathrm{ml}$ of sterile deionized water. Serial dilutions are prepared in $9 \mathrm{ml}$ of sterile deionized water and plated on Nutrient Agar (NA). From the NA plates, representative colonies of all different morphologies are chosen at random, purified by sub-culturing and maintained in slants of NA. All culture works will be conducted aseptically.

Cultivation of the microorganism will be conducted under aerobic conditions in a medium containing Nutrient Broth. Inoculated culture will be incubated at $30^{\circ} \mathrm{C}$ in an incubator for $120 \mathrm{hr}$.

\subsubsection{Soil amendment}

The bacterial isolate $\left(5 \times 10^{7} \mathrm{CFU} / \mathrm{soil} \mathrm{g}\right)$ will be inoculated into $250 \mathrm{ml}$ Erlenmeyer flasks containing diverse culture medium as previously stated and aerobically cultivated at $30^{\circ} \mathrm{C}$ by the agitating at the speed of $150 \mathrm{rpm}$. The cells are harvested from the growth medium at early-stationary phase by centrifugation at 
$5000 \mathrm{rpm}$ for $10 \mathrm{~min}$ or filtering with Whatman No. 1 filter paper. After rinsing in deionized water the cells are again centrifuged or filtered. The cell could be diluted with deionized sterile water prior to use and it can be used as microbial reagent.

Batch incubation will be carried out with $10 \mathrm{~g}$ of $2-\mathrm{mm}$ sieved remediated soil (oven dried) and different microbial reagents with a number of mixing ratios in 50 $\mathrm{ml}$ sterile glass bottle.

Pot incubation will be conducted with spraying the microbial reagents to the remediated soils for 8 weeks with a week interval.

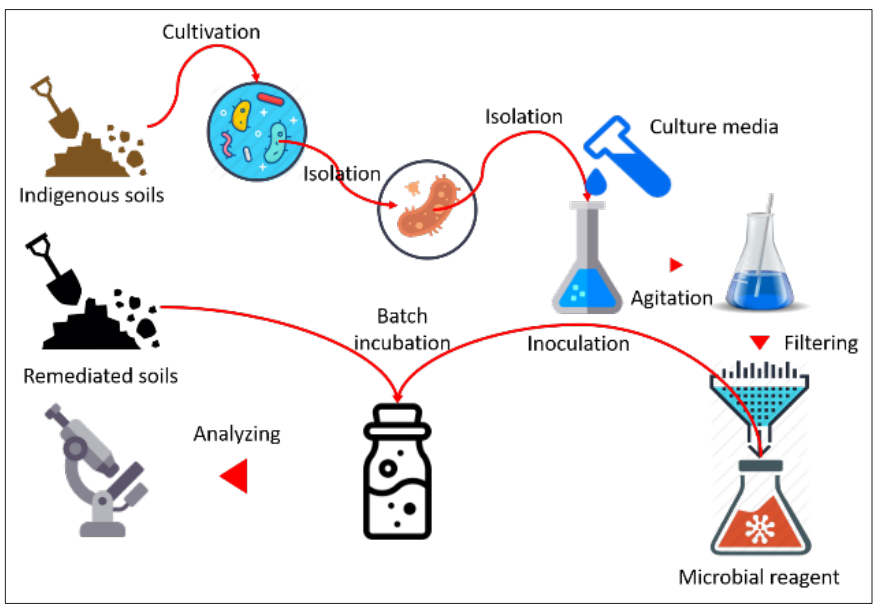

Figure 5 Schematic process of microbial amendment

\subsubsection{Soil and Microbes analysis}

Soil quality indicators selected by KS | ISO15176 depending on source of demands will be classified into fertility, strength, bioremediation according to physical, chemical, biological, ecological and engineering soil properties.

\subsubsection{Physical \& Engineering properties}

Bulk density and water content will be evaluated by USDA method.

Compressive strength will be evaluated with unconfined compression test. Shear strength will be estimated by direct shear test. Plastic index and hydraulic conductivity will be estimated by ASTM D4318-10 and D2434-68.

\subsubsection{Chemical properties}

Soil $\mathrm{pH}, \mathrm{EC}$, texture, exchangeable cations $(\mathrm{Ca}, \mathrm{K}, \mathrm{Mg}, \mathrm{Na})$, bulk density and water content will be estimated by USDA methods. CEC will be evaluated by US. EPA method 9081. Total nitrogen and available phosphate will be evaluated by UV/visible spectroscopic method. Organic matter will be estimated by WalkleyBlack method.

Heavy metals in the soils will be extracted using sequential extraction procedure and determined by atomic absorption spectrophotometry. Hydrocarbons in the soils will be extracted using a modified standard protocol of determining soil hydrocarbon 
content in soil according to ISO/DIS GC-method.

\subsubsection{Biological \& Ecological properties}

The microbial populations in the microcosm soils will be determined by a most probable number (MPN) procedure.

Five mustard (B. alva), and 3 pea ( $P$. sativum) will be added separately in triplicate to glass jars containing $20 \mathrm{~g}$ of soils re-wetted to $80 \%$ WHC. Lids are loosely screwed on to reduce evaporation but allow aeration and the seeds are left to germinate at $22^{\circ} \mathrm{C}, 80 \%$ humidity, $16 \mathrm{~h}$ full illuminance and $8 \mathrm{hr}$ darkness. When $>70 \%$ seeds in the non-contaminated soil germinated, the number of seeds germinated in all soil samples are recorded; this is after 4, 6 or 7 days exposure for mustard and pea, respectively. Seedling are dried at $105^{\circ} \mathrm{C}$ for $24 \mathrm{~h}$ and their mean dry weight calculated to assess effects (Dawson et al. 2007). Aboveground length of the mustard and pea will be estimated at $8^{\text {th }}$ days after seedling.

\subsubsection{Statistical analysis}

T-test will be conducted to all soils in process for evaluating effects. The experimental results will be statistically analyzed using SAS program with $0.05 \%$ significance level.

\section{Conclusions}

This study is aimed to establish a system to enhance effective utilization of the remediated soils reasonably by considering occurrence location, soil properties and soil criteria for source of demands. By doing so, it is intended to develop a soil quality improving device applied to the remediated soil from actual disposal plant, to design an expanded one in field scale, and to derive optimal driving factors.

Ultimately, in this way to a meaningful and significant extent, a correlation of soil properties and microbial amendment will be revealed in bench- and pilot- scale and it could be used to model a function of soil properties and microbial amendments depending on soil demands for effective recycling.

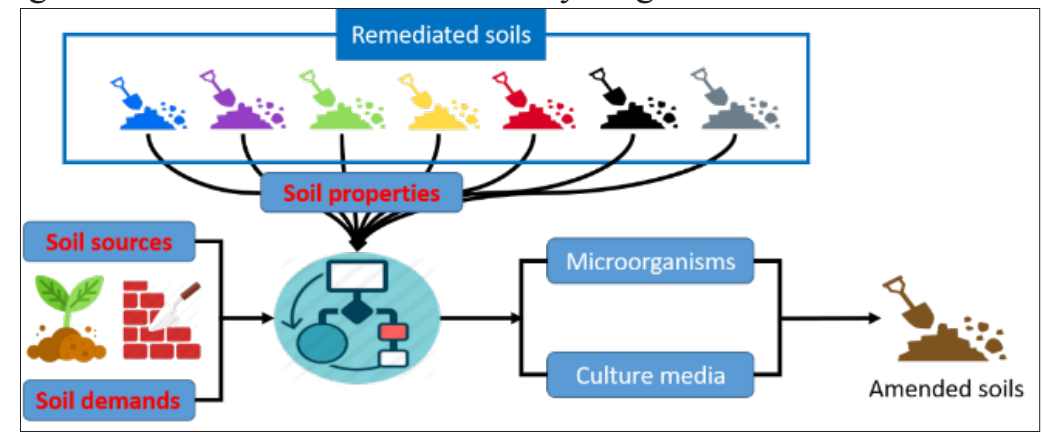

Figure 6 Schematic flow for modelling of microbial amendment 


\section{Acknowledgement}

This research is supported by the Basic Research Project of the National Research Foundation of Korea (NRF).

\section{References}

1. B. L. Kumar and D. V. R. S. Copal, Effective role of indigenous microorganisms for sustainable environment, Biotech 5, 867-876 (2015)

2. C. Switzer, S. Zihms, A Pape, A. Robson and C Knapp, Effects of aggressive remediation on soil properties and function, EGU General Assembly 15 (2013)

3. C. Switzer, S. G. Zihms and A. Tarantino, Effects of high temperatures on soil properties: Lessons to share from smouldering remediation experience, FLAMMA 6(1), 20-22 (2015)

4. G. T. Dejong, B. M. Mortensen, B. C. Martinez and D. C. Nelson, Bio-mediated soil improvement, Ecological Engineering 36, 197-210 (2010)

5. I. Maček, N. Šibanc, M. Kavšček and D. Lestan, Diversity of arbuscular mycorrhizal fungi in metal polluted and EDTA washed garden soils before and after soil revitalization with commercial and indigenous fungal inoculum, Ecological Engineering 95, 330-339 (2016)

6. J. J. C. Dawson, E. J. Godsiffe, I. P. Thompson, T. K. Ralebiso-Senior, K. S. Killham and G. I. Paton, Application of biological indicators to assess recovery of hydrocarbon impacted soils, Soil Biology \& Biochemistry 39, 164-177 (2007)

7. Kim GJ, Oh ST, Lee CH, Seo SK, Kang CH and Chang YY, Enhancement of biodegradation rate of petroleum hydrocarbons-contaminated soil with addition of organic composite nutrients and a chemical oxidation, J. Soil \& Groundwater Env. 13(3), 59-66 (2008)

8. Lee EJ, Lee SM, Lee GT, Kim IS and Kim YH, Application of effective microorganisms for bioremediation of crude oil spill in Taean, Korea, Journal of the Environmental Sciences 17(7), 795-799 (2008)

9. M. Lei, T. Chen, J. Yang, X. Zhou, Y. Wang and Y. Li, Optimized EDTA washing procedure to decontaminate heavy metals from soils in iron and steel work sites, Asian Journal of Chemistry 25(1), 37-41 (2013)

10. N. Sato, T. Higa, M. Shoya and S. Sugita, Some properties of concrete mixed with effective microorganisms and the on-site investigation of the completed structures, Hachinohe Institute of Technology, Japan (2000)

11. P. Wang, J. Li and H. Wang, Engineering properties of heavy metal contaminated soil affected by EDTA washing, EJGE 18, 3909-3918 (2013)

12. R. Dixit, Wasiullah, D. Malaviya, K. Pandiyan, U. B. Singh, A. Sahu, R. Shukla, B. P. Singh, J. P Rai, P. K. Sharma, H. Lade and D. Paul, Bioremediation of heavy metals from soil and aquatic environment: An overview of principles and criteria of fundamental processes, Sustainability 7, 2189-2212 (2015)

13. S. A. Khan, S. J. Tan, E. K. Abdul Rahman and Dk. N. Muneerah, Effect of hydrocarbon contamination and subsequent remedial treatment on the engineering properties of soil, Engineering and Technology (BICET 2014), $5^{\text {th }}$ International Conference on Brunei (2014)

14. S. S. Patil, E. M. Adetutu, J. Rochow, J. G. Mitchell and A. S. Ball, Sustainable remediation: electrochemically assisted microbial dechlorination of tetrachloroethene-contaminated groundwater, Microbial Biotechnology 7(1), 5463 (2014)

15. S. Zihms, C. Switzer, M. Karstunen and A. Tarantino, Understanding the effects 
of high temperature processes on the engineering properties of soils, Proceedings of the $18^{\text {th }}$ international conference on soil mechanics and geotechnical engineering, 3427-3430 (2013)

16. T. Higa and G. N. Wididana, The concept and theories of effective microorganisms, In J. F. Parr, S. B. Hornick, and C. E. Whiteman (ed.) Proceedings of First International Conference on Kyusei Nature Farming, U. S. Department of Agriculture, Washington, D. C., USA, 118-124 (1991)

17. X. W. Chen, X. Wang, X. Chen, Study on the extraction efficiency of heavy metals by chelates, Jiangsu Environmental Science and Technology 18(2), 9-10 (2005)

18. Yi YM, Oh CT, Kim GJ, Lee CH and Sung KJ, Changes in the physicochemical properties of soil according to soil remediation methods, J. Soil \& Groundwater Env. 17(4), 36-43 (2012)

19. Yi YM, Kim GJ and Sung KJ, Effect of soil remediation methods on the biological properties of soils, J. Soil \& Groundwater Env. 18(3), 73-81 (2013) 